\title{
ECONOMÍA Y POLÍTICA: ATADURAS DEL CANAL DURANTE CIEN AÑOS
}

\section{ECONOMIC AND POLITICAL TIES FOR CHANNEL ONE HUNDRED YEARS}

\author{
AUTOR \\ Alfonso Ojeda \\ Facultad de Ciencias Económicas. Universidad Complutense de Madrid. (España) \\ ojeda@cce.ucm.es
}

\section{RESUMEN}

El primero en plantear la construcción del Canal de Panamá fue el rey Carlos V, pero fue un fracaso, y finalmente fue construido por EEUU. Es la principal fuente de ingresos del país, sobretodo para los servicios financieros. Por lo tanto, su soberanía aporta beneficios económicos, políticos y estratégicos.

\section{PALABRAS CLAVE}

Carlos V- Economía- Canal de Panamá

\section{ABSTRACT}

The first to propose the construction of the Panama Canal was King Charles V, but was a failure, and was finally built by the U.S.. It is the main source of revenues, especially for financial services. Therefore, sovereignty provides economic, political and strategic. 


\section{KEY WORDS}

Carlos V- Economy- Panamá Canal

\section{ÍNDICE}

1. Pasado histórico.

2. Panamá en la actualidad.

El año 1999 ofrece dos acontecimientos similares de gran transcendencia internacional. China y Panamá recuperan sus potestades soberanas sobre Macao y el Canal, respectivamente. Se consuma un viejo sueño en sendos países, cuya virtualidad práctica consiste en sepultar largos años de humillación e injerencia extranjera en asuntos internos. Por lo que concierne al canal de Panamá, éste constituye un notable patrimonio que, hasta finales del 1999, aparece hipotecado, aunque ya es segura su próxima cancelación en favor de los intereses nacionales panameños. Esta observación no impide valorar el tránsito interoceánico como un auténtico "servicio público internacional".

Si cupiera la posibilidad de resumir los intereses nacionales que han aflorado en torno al canal, es decir, intereses en relación con la construcción de una vía de tránsito entre las dos orillas oceánicas, deberíamos concluir que existen básicamente dos clases de intereses: el propio del país donde se construye y los intereses ajenos. El interés propio pertenece a Panamá, mientras que los intereses foráneos han afectado a España, Francia y los Estados Unidos de América. 
REVISTA DE LA SEECI.

Ojeda, Alfonso (2000): Economía y política: ataduras del canal durante cien años. No 6. Noviembre. Año IV. Páginas: 32-39.

ISSN: 1576-3420 DOI: http://dx.doi.org/10.15198/seeci.2000.6.32-39

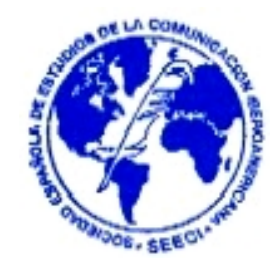

\section{Pasado histórico.}

Desde tiempos remotos el Istmo de Panamá fue utilizado para transferir personas y mercancías de un océano a otro (Atlántico y Pacífico). Su situación geoestratégica resulta, sin la menor duda, fundamental. Se trata de un cruce de culturas y rutas. Sin la existencia del canal los buques tendrían que realizar una penosa travesía marítima por el cono sur y atravesar el peligroso cabo de Hornos. Si prescindimos de la utilidad que reporta el canal, la conexión entre los dos océanos puede suponer un importante encarecimiento de los fletes marítimos e implicar una pérdida de tiempo próxima a dos semanas.

Ya en 1534 el emperador Carlos V ordenó un estudio para la construcción de un canal, que obviamente estaba fuera de sus posibilidades. Las dificultades orográficas, así como la falta de tecnología y conocimientos de ingeniería hacían el proyecto más ilusorio que real. Sin embargo, se puedo construir una calzada, una vía de piedra existen restos en el camino de Cruces- para transportar el oro que se extraía de Perú y se embarcaba por el Atlántico hasta España.

Los proyectos necesitaban madurar con el paso del tiempo. Pasaron tres siglos cuando en 1880 el ingeniero Fernando de Lesseps, el constructor del Canal de Suez, realizó una suscripción de acciones en Francia para construir un Canal en Panamá. Los intentos franceses chocaron con insalvables dificultades hasta el extremo de abortar el ambicioso proyecto de Lesseps. Entre otras causas que desencadenaron el fracaso, cabe mencionar las siguientes:

- Insuficiencia de medios técnicos susceptibles de coronar con éxito semejante obra.

- La abrupta situación del terreno añadía un factor adicional de incertidumbre, 
REVISTA DE LA SEECI.

Ojeda, Alfonso (2000): Economía y política: ataduras del canal durante cien años. No 6. Noviembre. Año IV. Páginas: 32-39.

ISSN: 1576-3420 DOI: http://dx.doi.org/10.15198/seeci.2000.6.32-39

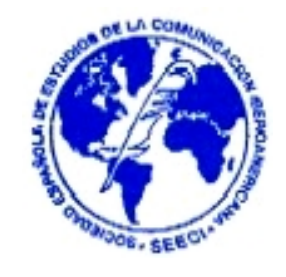

pues implicaba nada menos que el encarecimiento del proyecto $y$, especialmente, una dificultad mayor a las condiciones habituales de trabajo.

- Las enfermedades tropicales, especialmente la malaria, devastaban la mano de obra existente.

- Por lo demás, una deficiente administración de los recursos económicos existentes hizo naufragar un proyecto tan ambicioso como necesario.

Posteriormente entra a escena los Estados Unidos con su definitivo intento. Dicho país ayuda a Panamá a emanciparse de Colombia. Washington y Panamá firman en 1903 un Tratado según el cual Estados Unidos compra los derechos de la compañía francesa del Canal por cuarenta millones de dólares USA. En 1904 se inician las obras ante una expectación máxima toda vez que el coloso norteamericano había tomado el relevo de la amplia operación de ingeniería. El monumental proyecto finaliza diez años más tarde con un coste estimado algo inferior a cuatrocientos millones de dólares USA y el empleo de 75.000 y trabajadores.

El canal tiene ochenta kilómetros de largo y ya han transcurrido por sus aguas más de 700.000 buques. Es de confiar que durante el próximo siglo se incremente el tráfico hasta alcanzar niveles exponenciales, máxime cuando la globalización económica hace que el intercambio mercantil se dispare en virtud de la preconizada ruptura de las fronteras comerciales. Panamá tiene que saber aprovechar esa importante renta de situación a través de la ampliación y modernización de sus servicios. La gestión y explotación económica del canal se ha realizado por los norteamericanos. No siempre las relaciones entre ambos países han transcurrido por la senda del entendimiento y los vínculos de amistad. Bien al contrario, el futuro del canal ha desatado notables controversias. Incluso en forma de atentado o injerencia a la propia soberanía panameña. 


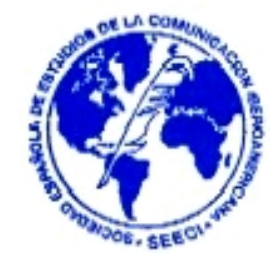

\section{Panamá en la actualidad.}

Un nuevo capítulo, desde luego más esperanzador, se abre en 1977 cuando los famosos tratados Torrijos-Carter permiten dar validez jurídica a la transferencia plena del canal en favor de los intereses nacionales panameños. Dicha transferencia tendrá lugar el 31 de diciembre de 1999. Afortunadamente no se prevén problemas insolubles de transición, toda vez que se ha trabajado conjuntamente a los efectos de verificar el relevo de gestión de forma eficiente y adecuada.

En alguna ocasión se ha comentado que el canal es para los panameños lo que el petróleo es para Arabia Saudí o el turismo para España. Ahora bien, el monocultivo económico no resulta aconsejable, ya que una crisis que afecte a semejante valor productivo puede originar serias consecuencias a la economía nacional. Hoy día se tiende a la diversificación económica aprovechando las ventajas competitivas existentes en cada país.

Aunque el canal suponga uno de los primeros activos nacionales -nadie puede cuestionarlo con la suficiente solvencia-, la economía panameña está cada día más diversificada. Si examinamos los distintos rubros de producción e intercambio observaremos que en materia agrícola aparecen distintas mercaderías, como la banana, el tabaco, la caña de azúcar, el café o el arroz. Todos ellos constituyen importantes actividades económicas al margen del canal. Por lo que concierne a la minería, Panamá produce oro y plata, así como sal. La industria está centrada entre otras líneas de producción, al calzado, textil, cemento o al refino del petróleo.

Se infiere, pues, que la economía panameña no sólo aparece supeditada a la gestión y explotación de su canal. Pero donde hay que resaltar más el gran avance económico de este país en el sector servicios, muy particularmente los servicios financieros. Panamá se ha convertido en un centro privilegiado para los inversores 
REVISTA DE LA SEECI.

Ojeda, Alfonso (2000): Economía y política: ataduras del canal durante cien años. No 6. Noviembre. Año IV. Páginas: 32-39.

ISSN: 1576-3420 DOI: http://dx.doi.org/10.15198/seeci.2000.6.32-39

internacionales. Entre otras razones que explican semejante devenir, hay que reflejar las siguientes:

- Excelente situación geo-estratégica.

- Gobierno democrático y respeto al Estado de Derecho.

- Legislación favorable a las inversiones extranjeras, incentivando la afluencia de nuevos capitales $y$, en el marco jurídico vigente, la repatriación de beneficios.

- El sistema tributario otorga confianza a los contribuyentes, consagrándose el principio de la territorialidad fiscal, de manera que nunca se ha gravado ingresos fuera de Panamá, ni siquiera a ciudadanos residentes o locales.

- El Derecho mercantil abre oportunidades a los empresarios y comerciantes en función del escaso intervencionismo público.

- Las sociedades mercantiles pueden constituirse con relativa celeridad y el coste burocrático resulta razonable.

- El dólar norteamericano circula con bastante profusión, no existiendo control de cambios que dificulte la circulación de esta divisa como moneda de curso legal.

- Opera una notable zona franca con capacidad para atraer nuevas inversiones.

- Goza de una bolsa de valores programada para incluir valores de ámbito internacional.

- El secreto bancario está muy protegido por las autoridades nacionales. 
REVISTA DE LA SEECI.

Ojeda, Alfonso (2000): Economía y política: ataduras del canal durante cien años. No 6. Noviembre. Año IV. Páginas: 32-39.

ISSN: 1576-3420 DOI: http://dx.doi.org/10.15198/seeci.2000.6.32-39

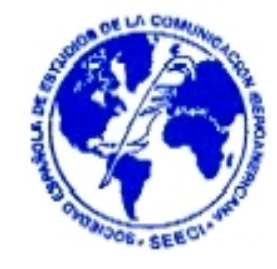

- Panamá alcanza el primer puesto mundial en el registro de buques.

Existe un trámite administrativo rápido y económico para el registro de naves bajo bandera panameña. En realidad, dicha bandera es objeto de extensa utilización por las compañías navieras internacionales gracias a los escasos impuestos que se abonan en comparación con los demás países.

Convendría concluir señalando que Panamá ha sufrido una crisis económica muy profunda, exigiendo sacrificios a la población a fin de restablecer la situación. La esperanza se abre, no obstante, al final del milenio. Acaso no vuelva a encontrarse con una situación tan ventajosa para coronar con garantías de éxito sus planes de prosperidad nacional.

Así y todo, la plena soberanía sobre el canal puede reportar un conjunto de beneficios:

1. Beneficios económicos derivados de la amplia actividad, directa o indirecta, que genera la explotación del canal.

2. Beneficios políticos, toda vez que hasta cierto punto se crea un nuevo panorama al romperse la dependencia nacional frente a los Estados Unidos. No pocos intelectuales panameños han celebrado la ruptura del colonialismo económico que ha sufrido Panamá durante este siglo. Sea cual fuere la valoración final, hay que reconocer los nuevos aires de orgullo nacional entre los panameños al recuperar todas las potestades soberanas en beneficio de la nación. Acaso la ciudadanía tuvo que pagar un alto precio -en términos de soberanía- para conseguir unos resultados que ahora se encuentran al alcance de su mano. Incluso las relaciones con los Estados Unidos deben volverse menos recelosas y 
más cooperativa en favor de los intereses mutuos. Washington necesita a Panamá tanto como éste necesita al otro país. Una vez cimentadas las relaciones bilaterales sobre el principio de igualdad -tarea no siempre fácil- Panamá reforzará su amistad con su socio norteamericano. Cuestión distinta es la necesidad de mantener abierto el canal para todos los buques sin posibilidad de restringir su acceso en función de discriminaciones o arbitrariedades de carácter político o económico.

3. El canal se convierte en un centro estratégico de primera magnitud al margen de una superpotencia. El canal se convierte en la antesala, 0 , si se quiere, en la puerta de entrada y salida a los océanos. De ahí que en el próximo siglo se consagre la doctrina del canal abierto para uso y beneficio de toda la humanidad. 